\title{
A systematic review of the effects and mechanisms of preoperative $5 \alpha$-reductase inhibitors on intraoperative haemorrhage during surgery for benign prostatic hyperplasia
}

\begin{abstract}
Huan-Tao Zong ${ }^{1}$, Xiao-Xia Peng ${ }^{2}$, Chen-Chen Yang ${ }^{1}$ and Yong Zhang ${ }^{1}$
$5 \alpha$-reductase inhibitors ( $5 \alpha$-RIs), including finasteride and dutasteride, are commonly used medical therapies for benign prostatic hyperplasia (BPH). Many studies reported that preoperative $5 \alpha-\mathrm{RI}$ had impact on intraoperative haemorrhage during surgery for BPH, but it was still in controversial. So, we conducted a systematic review of the effects and mechanisms of $5 \alpha$-RIs on intraoperative bleeding for BPH. MEDLINE, EMBASE, the Cochrane Controlled Trail Register of Controlled Trials and the reference lists of retrieved studies were searched in the analysis. Sixteen publications involving 15 different randomized controlled trials (RCTs) and a total of 1156 patients were used in the analysis, including 10 RCTs for finasteride and five RCTs for dutasteride. We found that preoperative finasteride treatment decreases microvessel density (MVD) in resected prostate specimens. Total blood loss, blood loss per gram of resected prostate tissue and decreases in haemoglobin were all greatly reduced in the finasteride group as compared to controls. Dutasteride appeared to have no effect on bleeding. This meta-analysis shows that preoperative finasteride treatment could decrease intraoperative haemorrhage during surgery for BPH. Preoperative dutasteride had no effect on intraoperative haemorrhage, but further high-quality prospective studies are still needed to confirm this observation.
\end{abstract}

Asian Journal of Andrology (2011) 13, 812-818; doi:10.1038/aja.2011.86; published online 5 September 2011

Keywords: $5 \alpha$-reductase inhibitor; benign prostate hyperplasia; haemorrhage; meta-analysis; microvessel density

\section{INTRODUCTION}

$5 \alpha$-reductase inhibitors ( $5 \alpha$-RIs), including finasteride and dutasteride, are commonly used medical therapies for benign prostatic hyperplasia (BPH). Finasteride, a type II $5 \alpha$-RI, blocks the conversion of testosterone to dihydrotestosterone. Inhibition of $5 \alpha$-reductase reduces the concentration of dihydrotestosterone in the prostate, which results in a decreased volume of the prostate, improved urinary flow and a decline in the incidence of acute urinary retention and the need for surgery. ${ }^{1}$ Recently, several studies have demonstrated that finasteride interferes with angiogenesis in the prostate, which results in tissue regression. ${ }^{2}$ Finasteride is also efficacious in decreasing gross haematuria caused by $\mathrm{BPH}$ that can lead to clot retention and the need for blood transfusion when prolonged. ${ }^{3,4}$ However, the ability of finasteride to decrease blood loss during surgical interventions for $\mathrm{BPH}$ and its mechanisms of action remain controversial. ${ }^{5-15}$ Although one meta-analysis focused on the effects of preoperative finasteride on reducing bleeding during transurethral resection of prostate (TURP), ${ }^{16}$ the number of experiments included was insufficient and the underlying mechanisms for these treatment effects were not considered.

Dutasteride, a new member of $5 \alpha$-RI group, offers the most complete inhibition of $5 \alpha$-reductase because it blocks both type I and II receptors; ${ }^{17}$ however, its effects on intraoperative bleeding during treatment for $\mathrm{BPH}$ and its mechanisms remain controversial, and to date no meta-analysis of these effects has been conducted. ${ }^{18-22}$

The goal of the present study was to perform a meta-analysis to evaluate the effects of finasteride and dutasteride on intraoperative bleeding during transurethral management of $\mathrm{BPH}$, which will resolve some of the remaining controversies over the use of these drugs.

\section{MATERIALS AND METHODS}

Inclusion criteria

Randomized controlled trials (RCTs) that met the following criteria were included: (i) the study referred to the effect of preoperative $5 \alpha$ RIs on bleeding during the intraoperative management of BPH and alterations of microvessel density (MVD) within the resected prostatic specimens; (ii) the study provided sufficient data for analysis, including the mean values and the standard deviations (s.d.s) of the MVDs and blood loss volumes; and (iii) the full text of the study could be accessed. If these inclusion criteria were not met, the studies were excluded from the analysis.

\section{Search strategy}

MEDLINE (from 1966 to June 2010), EMBASE (from 1974 to June 2010), the Cochrane Controlled Trail Register of Controlled Trials and 
the reference lists of retrieved studies were searched to identify RCTs that referred to the effects of preoperative treatment with $5 \alpha$-RIs on bleeding during the intraoperative management of $\mathrm{BPH}$ and also the mechanism of action for these drugs. The following search terms and acronyms were used: finasteride, dutasteride, bleeding, TURP, MVD and $\mathrm{BPH}$.

\section{Trial selection}

Two reviewers independently scanned the search results for potentially relevant studies and retrieved the full text of these articles. In the event that they had been published in more than one location, experimental data were used only once. Together, the authors discussed each of the RCTs that were included and opted to exclude studies that either failed to meet the inclusion criteria or could not be agreed upon by the authors. A flow chart of study selection is presented in Figure 1.

\section{Quality assessment}

The methodological quality of each study was assessed according to how patients were allocated to the arms of the study, concealment of allocation procedures, blinding and data loss due to attrition. The studies were then classified qualitatively according to the guidelines published in the Cochrane Handbook for Systematic Reviews of Interventions 5.0.2. ${ }^{23}$ Based on the quality-assessment criteria, each study was rated and assigned to one of the following three broad quality categories: A: if all quality criteria were adequately met, the study was deemed to have a low risk of bias; B: if one or more of the quality criteria was only partially met or unclear, the study was deemed to have a moderate risk of bias; or C: if one or more of the criteria were not met, inadequately met, or not included, the study was deemed to have a high risk of bias. Sensitivity analyses were then performed on the basis of whether these quality factors were adequate, inadequate or unclear. Differences were resolved by discussion among the authors.

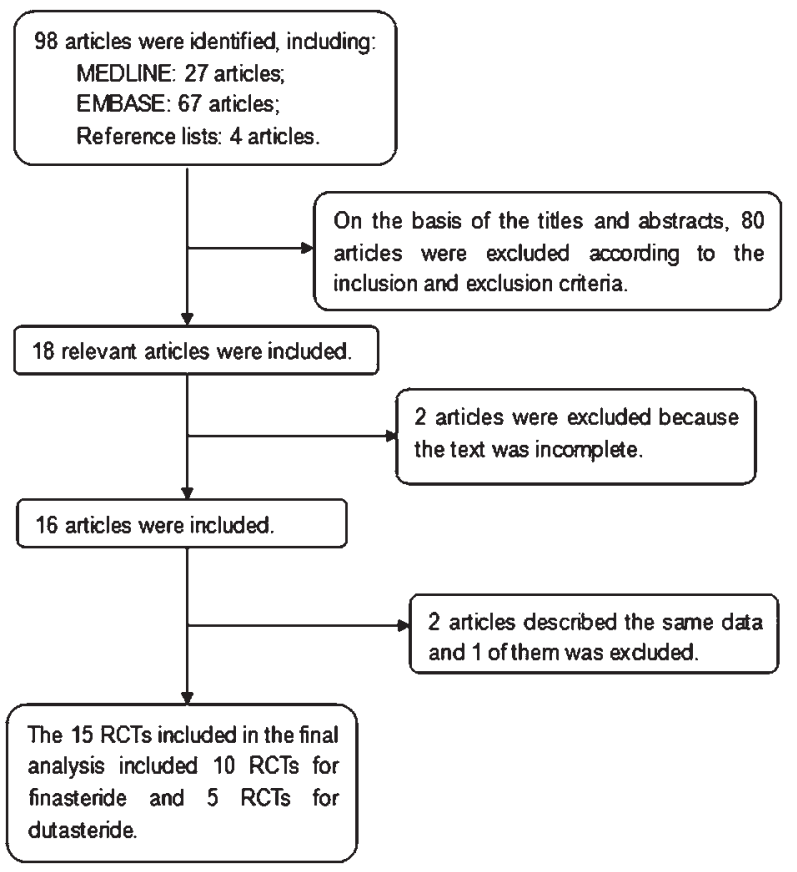

Figure 1 Flow chart illustrating the numbers of studies included in the metaanalysis. RCT, randomized controlled trial.

\section{Data extraction}

Two reviewers independently extracted data from the published papers for analysis. The following information was collected: (i) the name of the first author and the publication year; (ii) the study design and sample size; (iii) duration and type of preoperative drug treatment; (iv) the source of patients; (v) indicators of blood loss during treatment including total blood loss, blood loss/weight, haemoglobin $\mathrm{Hb}$ ) alterations and $\mathrm{Hb}$ alteration/weight; and (vi) MVD of the resected prostate specimens. Disagreements were resolved by consultation with an additional author.

\section{Statistical analysis}

The meta-analysis of comparable data was carried out using Review Manager 5.0.2 (The Nordic Cochrane Centre, The Cochrane Collaboration, 2008). Due to the large number of plots, we combined the six forest plots into two plots using Adobe Photoshop CS3 (Adobe Systems Inc., San Jose, CA, USA; Figures 2 and 3). We referred to these funnel plots for the meta-analysis, but they did not provide any evidence of a publication bias (Figure 4). Egger's and Macaskill's tests were also used to identify potential publication bias in the studies, and both tests confirmed that there was no publication bias $(P=0.7586$ and $P=0.5240$, respectively; Table 1 ).

Results were expressed as the mean difference for continuous outcomes with $95 \%$ confidence intervals. The standard mean difference was used if the outcome data were not recorded in a consensus method. A 'fixed-effects' statistical model was used if there was no conspicuous heterogeneity, and a 'random-effects' model was used if heterogeneity was detected. Tests for heterogeneity were performed using Chi-square tests with significance level set at $P<0.1$. A sensitivity analysis was performed to explore whether the heterogeneity was a result of low study quality, and the lowest-quality trials were excluded.

\section{RESULTS}

\section{Characteristics of individual studies}

The database search and reference lists of retrieved studies found 98 potential articles to be used in our meta-analysis. Based on the inclusion and exclusion criteria, 80 articles were excluded after simply reading the titles and abstracts of the articles and two articles were excluded because they lacked a full text. In all, 16 articles with 15 RCTs were included in the analysis, with $10 \mathrm{RCTs}^{5-15}$ for finasteride and 5 RCTs $^{18-22}$ for dutasteride (Figure 1). The trials in these articles had been conducted in 13 different countries across Europe, North America and Asia. A majority $(60 \%, 9 / 15)$ of the studies we analysed had a sample size larger than 50; the remaining $40 \%(6 / 15)$ had a sample size smaller than 50, but larger than 25 . Baseline characteristics of the 15 individual studies included in our meta-analysis are listed in Table 2 .

\section{Quality of individual studies}

Among the studies included in the analysis, three described the randomisation processes that they had employed. ${ }^{8,11,15}$ Seven out of 15 studies used blinding methods, ${ }^{5,9,10,14,18,19,21}$ including four doubleblinded RCTs. ${ }^{10,12,18,19}$ One of these 15 studies performed a power calculation to assess the optimal sample size, ${ }^{11}$ and one used an intention-to-treat analysis. ${ }^{22}$ The quality levels of the 15 identified studies ranged from $\mathrm{A}$ to $\mathrm{C}$.

\section{Clinical outcome after preoperative finasteride treatment}

Blood loss during management of BPH. Six studies of the effects of preoperative finasteride on total blood loss during surgery for $\mathrm{BPH}$ 


\begin{tabular}{|c|c|c|c|c|c|c|}
\hline & $\begin{array}{l}\text { Treatment } \\
\text { Mean } \pm \text { s.d. }\end{array}$ & $\begin{array}{l}\text { No. in } \\
\text { group }\end{array}$ & $\begin{array}{l}\text { Control } \\
\text { Meants.d. }\end{array}$ & $\begin{array}{l}\text { No. in } \\
\text { group }\end{array}$ & $\begin{array}{r}\text { Mean diff } \\
95^{\circ}\end{array}$ & $\begin{array}{l}\text { erence (Std) } \\
{ }_{0} \mathrm{Cl}\end{array}$ \\
\hline \multicolumn{7}{|l|}{ Blood loss (Fixed, ml) } \\
\hline Sandfeldt et al. 2001 [12] & $320.50 \pm 236.80$ & 263 & $368.35 \pm 257.00$ & 029 & & \\
\hline Liu et al. 2003 [6] & $135.8 \pm 92.90$ & 50 & $245.14 \pm 168.90$ & 050 & $\longrightarrow-$ & \\
\hline Li et al. 2004 [7] & $360.9 \pm 157.9$ & 40 & $455.8 \pm 166.4$ & 40 & & \\
\hline Özdal et al. 2005 [5] & $173.47 \pm 86.18$ & 202 & $235.46 \pm 67.03$ & 20 & $\longrightarrow$ & \\
\hline Total No. & & 136 & & 139 & & \\
\hline \multicolumn{7}{|c|}{ Total (95\% Cl): $-83.33[-114.28,-52.37]$} \\
\hline \multicolumn{7}{|c|}{$P<0.00001 ; l^{2}=0 \%$} \\
\hline \multicolumn{7}{|c|}{ Blood loss per g prostate (Random, $\mathrm{ml} \mathrm{g}^{1}$ ) } \\
\hline Sandfeldt et al. 2001 [12] & $15.47 \pm 8.73$ & 26 & $17.88 \pm 10.85$ & 29 & & \\
\hline Liu et al. $2003[6]$ & $7.85 \pm 3.88$ & 50 & $11.24 \pm 4.30$ & 50 & & \\
\hline Li et al. $2004[7]$ & $21.8 \pm 1.7$ & 40 & $22.9 \pm 2.2$ & 40 & & \\
\hline Özdal et al. 2005 [5] & $7.60 \pm 2.37$ & 20 & $13.99 \pm 4.16$ & 20 & & \\
\hline Total No. & & 136 & & 139 & & \\
\hline \multicolumn{7}{|c|}{ Total (95\% Cl): $-3.44[-5.93,-0.75]$} \\
\hline \multicolumn{7}{|c|}{$P=0.01 ; 1^{2}=87 \%$} \\
\hline \multicolumn{7}{|l|}{ Hb alteration (Fixed, $g d l^{\prime}$ ) } \\
\hline Liu et al.2003 [6] & $1.86 \pm 1.41$ & 50 & $3.17 \pm 2.03$ & 50 & & \\
\hline Özdal et al. 2005 [5] & $1.88 \pm 0.93$ & 20 & $3.19 \pm 1.18$ & 20 & & \\
\hline Total No. & & 70 & & 70 & & \\
\hline \multicolumn{7}{|c|}{ Total $(95 \% \mathrm{Cl}):-1.31[-1.78,-0.84]$} \\
\hline \multicolumn{7}{|c|}{$P<0.00001 ; I^{2}=0 \%$} \\
\hline \multicolumn{7}{|c|}{ Microvessel density (Random) } \\
\hline Donohue et al. 2002/2005 [9 & $9,14] 60 \pm 2.55$ & 31 & $71 \pm 3.57$ & 33 & $=$ & \\
\hline Häggström et al. 2001 [15] & $37 \pm 1.825$ & 15 & $45 \pm 3.470$ & 13 & $=$ & \\
\hline Liu et al. 2003 [6] & $21.4 \pm 9.7$ & 50 & $33.4 \pm 11.2$ & 50 & . & \\
\hline Memis et al. 2007 [13] & $14.2 \pm 7.1$ & 13 & $19.8 \pm 9.7$ & 17 & . & \\
\hline Total No. & & 109 & & 113 & & \\
\hline \multicolumn{7}{|c|}{ Total $(95 \% \mathrm{Cl}):-9.60[-11.93,-7.28]$} \\
\hline \multicolumn{7}{|c|}{$P<0.00001 ; I^{2}=63 \%$} \\
\hline & & & & & $\begin{array}{c}-100-50 \\
\text { Fin }\end{array}$ & 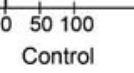 \\
\hline
\end{tabular}

Figure 2 Effects of preoperative finasteride treatment on bleeding during TURP and its mechanisms. The volume of prevented blood loss ranged from 47.85 to $109.34 \mathrm{ml}(P<0.00001)$, the volume of blood loss prevented per gram of resected prostate tissue ranged from 1.1 to $6.39 \mathrm{ml} \mathrm{g}^{-1}$ ( $P=0.01$ ) (the range of prevented blood loss volume and blood loss volume per gram of resected prostate tissue were calculated on the reciprocal mean of different trials). Decreases in $\mathrm{Hb}$ were significantly less in the finasteride group $(P<0.00001)$. Microvessel density in the finasteride group was lower than that in the control group $(P<0.00001)$. $\mathrm{Cl}$, confidence interval; $\mathrm{Hb}$, haemoglobin; TURP, transurethral resection of prostate.

\begin{tabular}{|c|c|c|c|c|c|}
\hline & $\begin{array}{l}\text { Treatment } \\
\text { Meants.d. }\end{array}$ & $\begin{array}{l}\text { No. in } \\
\text { group }\end{array}$ & $\begin{array}{l}\text { Control } \\
\text { Meants.d. }\end{array}$ & $\begin{array}{l}\text { No. in } \\
\text { group }\end{array}$ & $\begin{array}{l}\text { Mean difference } \\
\text { IV, Fixed, } 95 \% \mathrm{CI}\end{array}$ \\
\hline Boccon-Gibod et al. 2005 [18] & $1.944 \pm 1.816$ & 32 & $1.401 \pm 1.021$ & 27 & \\
\hline Hahn et al. $2007[19]$ & $2.550 \pm 0.046$ & 71 & $2.550 \pm 0.049$ & 70 & \\
\hline Total No & & 103 & & 97 & \\
\hline \multicolumn{6}{|l|}{ Total $(95 \% \mathrm{Cl}): 0.00[-0.02,0.02]$} \\
\hline \multicolumn{6}{|l|}{$P=0.98 ; l^{2}=52 \%$} \\
\hline & & & & -2 & 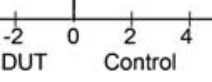 \\
\hline
\end{tabular}

Figure 3 Effects of preoperative dutasteride on bleeding during transurethral interventions for $\mathrm{BPH}$. No effect of preoperative dutasteride treatment on bleeding during transurethral intervention for $\mathrm{BPH}$ was found $(P=0.98)$. $\mathrm{BPH}$, benign prostatic hyperplasia; $\mathrm{Cl}$, confidence interval; DUT, dutasteride.

were identified, which involved 486 participants (240 in the treatment group and 246 in the control group); conclusions differed across studies. ${ }^{5-8,11,12}$ No significant differences were found with respect to the resection weights of the samples. Two of the six articles were not included in the meta-analysis because they failed to report SD. ${ }^{8,11}$ In total, only four trials were included in the meta-analysis, representing 


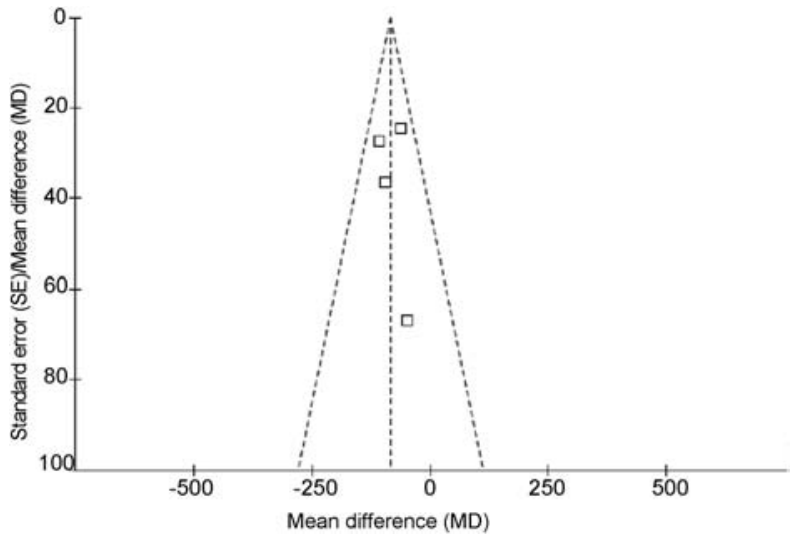

Figure 4 Funnel plot of the studies represented in our meta-analysis. This funnel plot provided us with a qualitative estimation of publication bias of the studies, and no evidence of bias was found.

a cohort of 275 participants (136 in the treatment group and 139 controls) (Figure 2). ${ }^{5-7,12}$ Among the four included studies, three RCTs supported the notion that preoperative finasteride could decrease bleeding during transurethral interventions for $\mathrm{BPH},{ }^{5-7}$ whereas one study did not. ${ }^{12}$ According to our analysis, no heterogeneity was found among the three trials $(P=0.56)$, and thus a fixedeffects model was chosen for the analysis. Based on our analysis, the volume of blood loss saved ranged from 47.85 to $109.34 \mathrm{ml}$ $(P<0.00001)$ (Figure 2).

Blood loss per gram of resected prostate tissue. Four studies on the effects of preoperative finasteride on blood loss per gram of resected prostate tissue during surgery for BPH were identified for a total of 275 participants (136 in the treatment group and 139 controls) (Figure 2). ${ }^{5-7,12}$ The volume of blood loss per gram of resected prostate tissue ranged from 1.1 to $6.39 \mathrm{ml} \mathrm{g}^{-1}(P=0.01),{ }^{5-7}$ and no conspicuous difference was observed in the remaining study ${ }^{12}$ (Figure 2). Heterogeneity existed among the three trials as determined using the random-effects model $(P<0.0001)$.

$\mathrm{Hb}$ change after surgery. Three studies were identified changes in $\mathrm{Hb}$, including 208 patients overall (102 in the treatment group and 106 in control) (Figure 2). ${ }^{5,6,14}$ However, one trial was not included in the meta-analysis because it lacked SD values. ${ }^{14}$ There was no heterogeneity between the remaining two trials and therefore, the fixed-effects model was used $(P=1.00)$. According to the analysis, the decrease in $\mathrm{Hb}$ in the finasteride group was significantly lower than in the control group $(P<0.00001)$.

\section{Mechanisms of finasteride action}

Seven studies involving 655 participants referred to the MVD of the prostate tissues. However, only four of these seven studies presented SD values ${ }^{6,13-15}$ and were included in the meta-analysis (Figure 2). In three experiments, the MVD of the resected prostate tissue was lower in the treatment group than in the control group; ${ }^{6,14,15}$ no differences were found in the remaining one study. ${ }^{13}$ Overall, 222 participants (109 in the treatment group and 113 controls) were included in the meta-analysis. Heterogeneity did not exist among the studies $(P=0.04)$, so a random-effects model was chosen. The analysis revealed that the MVD of the resected prostate specimens was significantly lower in the finasteride group than in the control group $(P<0.00001)$.

\section{Clinical outcome with preoperative dutasteride}

Five RCTs involving two multicentre trials were identified. Only two RCTs referred to changes in $\mathrm{Hb}$ per gram of resected prostate. ${ }^{18,19} \mathrm{No}$ heterogeneity was detected among the studies $(P=0.15)$, and no significant differences were found between the treatment and control groups $(P=0.98$; Figure 3$)$. In the study conducted by Tuncel et al., ${ }^{20}$ total blood loss, blood loss/weight and $\mathrm{Hb}$ changes did not differ between the treatments and control groups ( $P=0.124,0.130$ and 0.912 , respectively). In addition, no difference in blood loss volume between treatment and control groups was found by Bepple et al. ${ }^{22}$ $(P=0.14)$.

MVD after treatment with dutasteride. Three studies that referred to MVD were identified. ${ }^{19-21}$ In the studies conducted by Tuncel et al. ${ }^{20}$ and $\mathrm{Ku}$ et al., ${ }^{21}$ the mean MVD of the resected prostate specimens were not significantly different between the treatment and control groups ( $P=0.401$ and 0.754 , respectively), and a similar outcome was also observed in Hahn et al. ${ }^{19}$

\section{DISCUSSION}

$5 \alpha$-RIs, including finasteride and dutasteride, are commonly used medical therapies for $\mathrm{BPH}$ and offer similar effects for treating lower urinary tract symptoms. ${ }^{24}$ Bleeding as a complication of the transurethral management of $\mathrm{BPH}$ is common both during and after surgery. The effects of finasteride and dutasteride on such bleeding and its mechanisms have been well studied, but the conclusions remain equivocal. The ability of preoperative finasteride to decrease blood loss has been observed in many studies, ${ }^{5-10}$ but these effects are not found in all RCTs. ${ }^{11-15}$ For example, in the study conducted by Boccon-Gibod et al., ${ }^{18}$ preoperative treatment with dutasteride decreased bleeding during treatment for $\mathrm{BPH}$, but these findings were not consistent across studies. ${ }^{19-22}$

Our meta-analysis reviewed 15 contemporary RCTs involving 1156 participants ( 580 who were treated with $5 \alpha$-RIs and 576 patients in the control group). The results of this meta-analysis suggest that preoperative treatment with finasteride for 2-4 weeks could decrease bleeding during transurethral resection for $\mathrm{BPH}$, possibly because finasteride appears to decrease MVD of prostate tissue. In contrast, dutasteride administered before $\mathrm{BPH}$ treatment has no impact on MVD of prostate specimens or intraoperative bleeding.

Finasteride, a type II $5 \alpha$-RI, is a well-known inhibitor of the conversion of testosterone to dihydrotestosterone. Reduced expression of vascular endothelial growth factor (VEGF), a potent stimulator of angiogenesis, has been reported after finasteride treatment. ${ }^{25}$ One of

Table 1 Egger's test and Macaskill's test of the studies included in the meta-analysis

\begin{tabular}{|c|c|c|c|c|c|c|c|}
\hline Test & Std_eff/Eff_size & Coefficient & Standard error & $\mathrm{t}$ & $P>|t|$ & \multicolumn{2}{|c|}{$95 \%$ confidence interval } \\
\hline Egger's test & Slope & -0.94508 & 0.96382 & 0.35 & 0.4302 & -3.167664348 & 1.2775001936 \\
\hline & Bias & 1.36786 & 3.88901 & NA & 0.7586 & -7.600202806 & 10.335930666 \\
\hline Macaskill's test & Sample size & -0.00507 & 0.00662 & -0.77 & 0.5240 & -0.0203339 & 0.01019807 \\
\hline
\end{tabular}

Abbreviation: NA, not available. 


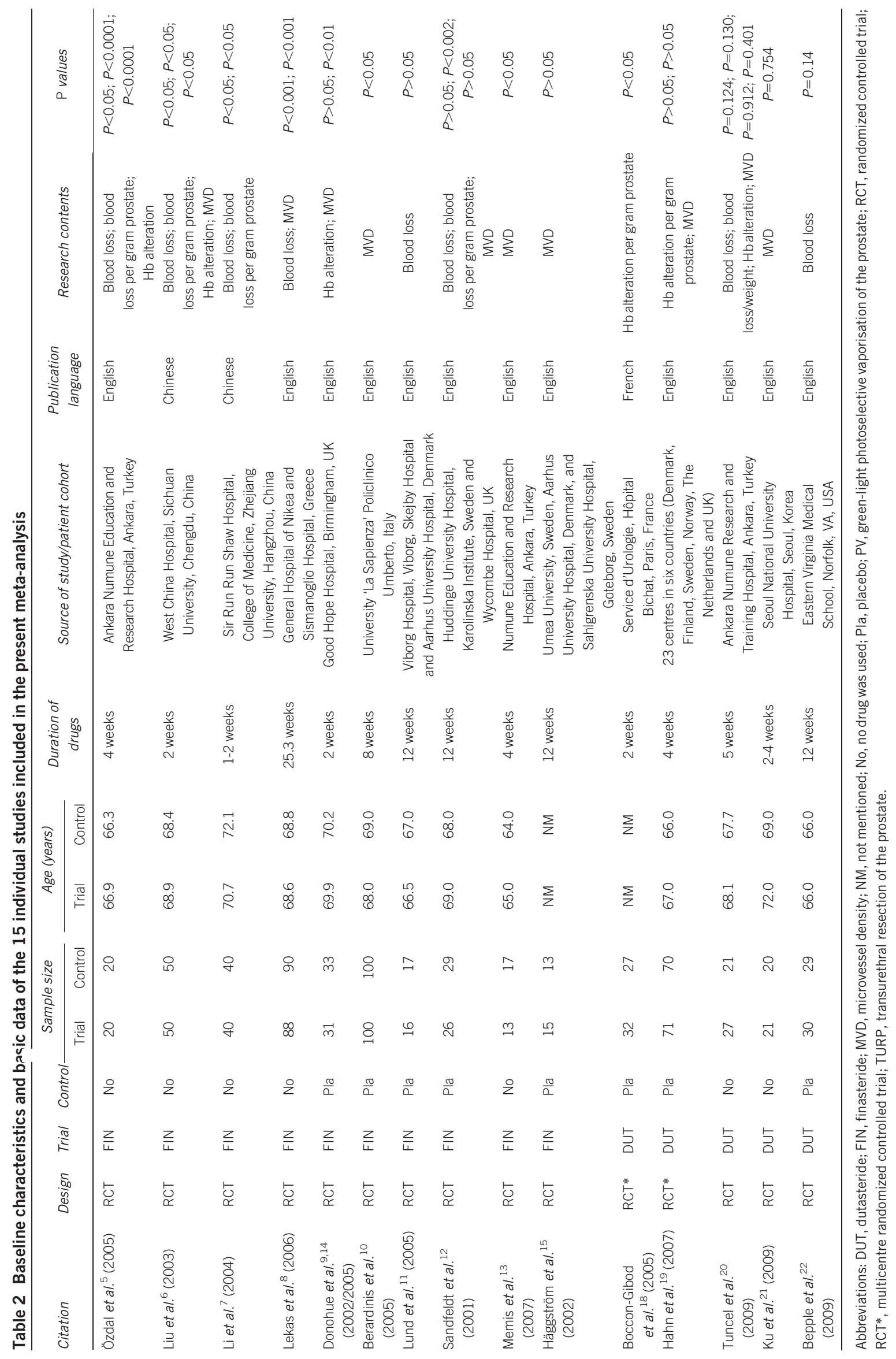


the possible mechanisms for the relationship between VEGF and finasteride is that the former is an androgen-controlled growth factor. ${ }^{26} \mathrm{MVD}$ is an indicator of vascularity and thus serves as a surrogate marker for bleeding. ${ }^{27}$ Based on our analysis of 10 RCTs that pertained to finasteride, we found that preoperative finasteride could significantly decrease MVD of the prostate tissue and reduce bleeding during BPH treatment. One possibility is that finasteride administered preoperatively for a duration from 2 weeks to 4 months reduces the expression of VEGF. In a study conducted by Liu et al., ${ }^{6}$ a similar effect was observed with only 1-2 weeks of preoperative finasteride treatment.

Dutasteride offers the most complete blockade of $5 \alpha$-reductase because it antagonizes both type I and II receptors. In theory, dutasteride should produce effects similar to finasteride. However, in our analysis, we did not find any differences between dutasteride treatment and control groups $(P=0.98)$. It may be that the sample sizes of the trials were not large enough to generate enough data for detecting significant effects. Furthermore, the distinct pharmacological functions of each of the two $5 \alpha$-RIs may be another factor that requires further research. Further high-quality studies are still needed to identify whether preoperative dutasteride actually affects the amount of bleeding during transurethral surgery for $\mathrm{BPH}$.

We found that preoperative finasteride treatment for 2-4 weeks decreased bleeding during transurethral resection for $\mathrm{BPH}$, and we suggested that this effect could be due to the ability of finasteride to decrease expression of VEGF and MVD in prostate tissue. Our results show that preoperative dutasteride had no effect on bleeding during transurethral procedures for BPH. As with all meta-analyses, it is important to consider certain caveats that accompany the findings. Publication bias may influence the results because negative data are less likely to be published. However, some of the published papers that we consulted contained negative results, ${ }^{11-13,15}$ and our funnel plot does not provide any evidence of publication bias. Our results from the Egger's and Macaskill's tests also confirms that there has been no publication bias ( $P=0.7586$ and $P=0.5240$, respectively; Table 1$)$. The quality of the experiments used for the meta-analysis varied, and for some analyses, the sample sizes were still not large enough to obtain significant results. Additionally, several of the RCTs did not offer SD values, which may be because the data were skewed in their distribution because experiments were not sufficiently powered. According to the quality-assessment scale that we developed, the quality of individual studies in the meta-analysis was variable; quality appears to be the main reason for heterogeneity among these studies, and this heterogeneity probably arose from several factors. Firstly, there were important differences in the adequacy of the randomisation process, blinding methodology, control group and the duration for which the drugs were used preoperatively. Secondly, study outcomes may have been measured by different methods. Thirdly, the level of the operators varied in the trials. Finally, potential selection biases could have influenced the homogeneity of the groups, and relatively small sample sizes limited statistical power for identifying true associations. When heterogeneity among individual studies is taken into account, this meta-analysis will be crucial for assessing the effects of $5 \alpha$-RIs on changes to MVD in prostate specimens and blood loss volumes during treatment of BPH. In consideration of the limited quality of the studies included in the analysis, we suggest that further experimental work should be rigorously designed, which includes allocation generation (e.g., random number tables, computer-generated random numbers, coin tossing and shuffling), allocation concealment (e.g., central randomisation; serially numbered, opaque and sealed envelopes), blinding method and use of intention-to-analysis. In addition, further high-quality prospective studies are needed to identify the mechanisms by which $5 \alpha$-RIs exert their actions.

\section{AUTHOR CONTRIBUTIONS}

YZ designed the research, interpreted the data and revised the paper. HTZ, XXP and CCY performed the data extraction, conducted the meta-analysis and drafted the paper. All of the authors approved the submitted and final versions of the manuscript.

\section{COMPETING FINANCIAL INTERESTS}

The authors declare that they have no competing financial interests.

\section{ACKNOWLEDGMENTS}

Financial support for our studies from the Research Fund of Capital Medical Development (No. 2009-2069) and Urological Backbone Fund of Beijing Municipal Health Bureau (No. 2009-3-15) is gratefully acknowledged.

1 Marks LS, Partin AW, Dorey FJ, Gormley GJ, Epstein JI et al. Long-term effects of finasteride on prostate tissue composition. Urology 1999; 53: 574-80.

2 Pareek G, Shevchuk M, Armenakas NA, Vasjovic L, Hochberg DA et al. The effect of finasteride on the expression of vascular endothelial growth factor and microvesse density: a possible mechanism for decreasing prostate bleeding in treated patients. J Urol 2003; 169: 20-3.

3 Puchner PJ, Miller MI. The effects of finasteride on hematuria associated with benign prostatic hyperplasia: a preliminary report. J Urol 1995; 154: 1779-82.

4 Sieber PR, Rommel FM, Huffnagle HW, Breslin JA, Agusta VE et al. The treatment of gross hematuria secondary to prostatic bleeding with finasteride. J Urol 1998; 159: 1232-3.

5 Özdal ÖL, Özden C, Benli K, Gokkaya S, Bulut S et al. Effect of short-term finasteride therapy on preoperative bleeding in patients who were candidates for transurethral resection of the prostate (TUR-P): a randomized controlled study. Prostate Cance Prostatic Dis 2005; 8: 215-8.

6 Liu XD, Yang YR, Lu YP, Zhang XH, Li FY et al. Preoperative finasteride on decreasing operative bleeding during transurethral resection of prostate. Chin J Urol 2003; 24 694-6.

$7 \mathrm{Li} \mathrm{GH}, \mathrm{He}$ ZF, Yu DM, Li XD, Chen ZD. Effect of finasteride on intraoperative bleeding and irrigating fluid absorption during transurethral resection of prostate: a quantitative study. J Zhejiang Univ (Med Sci) 2004; 33: 25860.

8 Lekas AG, Lazaris AC, Chrisofos M, Papatsoris AG, Lappas D et al. Finasteride effects on hypoxia and angiogenetic markers in benign prostatic hyperplasia. Urology 2006; 68: 436-41.

9 Donohue JF, Sharma H, Abraham R, Natalwala S, Thomas DR et al. Transurethral prostate resection and bleeding: a randomized, placebo controlled trial of the role of finasteride for decreasing operative blood loss. J Urol 2002; 168: 2024-6.

10 Berardinis ED, Antonini G, Busetto GM, Gentile V, Silverio FD et al. Reduced intraoperative bleeding during transurethral resection of the prostate: evaluation of finasteride, vascular endothelial growth factor, and CD34. Curr Prostate Rep 2005; 6 : 123-7.

11 Lund L, Ernst-Jensen KM, Tørring N, Nielsen JE. Impact of finasteride treatment on perioperative bleeding before transurethral resection of the prostate: a prospective randomized study. Scand J Urol Nephrol 2005; 39: 160-2.

12 Sandfeldt L, Bailey DM, Hahn RG. Blood loss during transurethral resection of the prostate after 3 months of treatment with finasteride. Urology 2001; 58: 972-6.

13 Memis A, Ozden C, Ozdal OL, Guzel O, Han O et al. Effect of finasteride treatment on suburethral prostatic microvessel density in patients with hematuria related to benign prostate hyperplasia. Urol Int 2008; 80: 177-80.

14 Donohue JF, Hayne D, Karnik U, Thomas DR, Foster MC. Randomized, placebo controlled trial showing that finasteride reduces prostatic vascularity rapidly within 2 weeks. BJU Int 2005; 96: 1319-22.

15 Häggström S, Tørring N, Møller K, Jensen E, Lund L et al. Effects of finasteride on vascular endothelial growth factor-a placebo controlled randomized study in $\mathrm{BPH}$ patients. Scand J Urol Nephrol 2002; 36: 182-7.

16 Zhu YC, Zhong L, Wei Q. Meta-analysis of finasteride for perioperative bleeding in patients undergoing transurethral resection of prostate. Chin J Evid-based Med 2008, 8: 456-60.

17 Roehrborn CG, Boyle P, Nickel JC, Hoefner K, Andriole G et al. Efficacy and safety of a dual inhibitor of 5-alpha-reductase types 1 and 2 (dutasteride) in men with benign prostatic hyperplasia. Urology 2002; 60: 434-41.

18 Boccon-Gibod L, Valton M, Ibrahim H, Comenducci A. Effect of dutasteride on reduction of intraoperative bleeding related to transurethral resection of the prostate. Prog Urol 2005; 15: 1085-9. 
19 Hahn RG, Fagerström T, Tammela TL, Trip OV, Beisland HO et al. Blood loss and postoperative complications associated with transurethral resection of the prostate after pretreatment with dutasteride. BJU Int 2007; 99: 587-94.

20 Tuncel A, Ener K, Han O, Nalcacioglu V, Aydin O et al. Effects of short-term dutasteride and Serenoa repens on perioperative bleeding and microvessel density in patients undergoing transurethral resection of the prostate. Scand J Urol Nephrol 2009; 43: 377-82.

$21 \mathrm{KuJH}$, Shin JK, Cho MC, Myung JK, Moon KC et al. Effect of dutasteride on the expression of hypoxia-inducible factor-1a,vascular endothelial growth factor and microvessel density in rat and human prostate tissue. Scand J Urol Nephrol 2009; 43: 445-53

22 Bepple JL, Barone BB, Eure G. The effect of dutasteride on the efficacy of photoselective vaporization of the prostate: results of a randomized, placebocontrolled, double-blind study (DOP trial). Urology 2009; 74: 1101-4.
23 Higgins JPT, Green S. Cochrane Handbook for Systematic Reviews of Interventions 5.0.2. Chichester: John Wiley \& Sons, Ltd; 2009.

24 Kaplan S, Chung D, Lee R, Melamed S, Te A. A 5 year study of the use 5-alpha reductase inhibitors in men with benign prostatic hyperplasia: finasteride has equal efficacy and prostate volume reduction but has less sexual side effects and breast enlargement than dutasteride. J Urol 2010; 183: e6923.

25 Monti S, Sciarra F, Adamo MV, Toscano V, Trotta MC et al. Prevalent decrease of the EGF content in the periurethral zone of BPH tissue induced by treatment with finasteride or f lutamide. J Androl 1997; 18: 488-94.

26 Haggstrom S, Lissbrant IF, Bergh A, Damber JE. Testosterone induces vascular endothelial growth factor synthesis in the ventral prostate in castrated rats. J Urol 1999; 161: 1620-5.

27 Foley SJ, Bailey DM. Microvessel density in prostatic hyperplasia. BJU Int 2000; 85: 70-3. 